\title{
Geometries of beauty
}

\section{Lynn Gamwell traces the millennia of symbiosis between mathematics and art.}

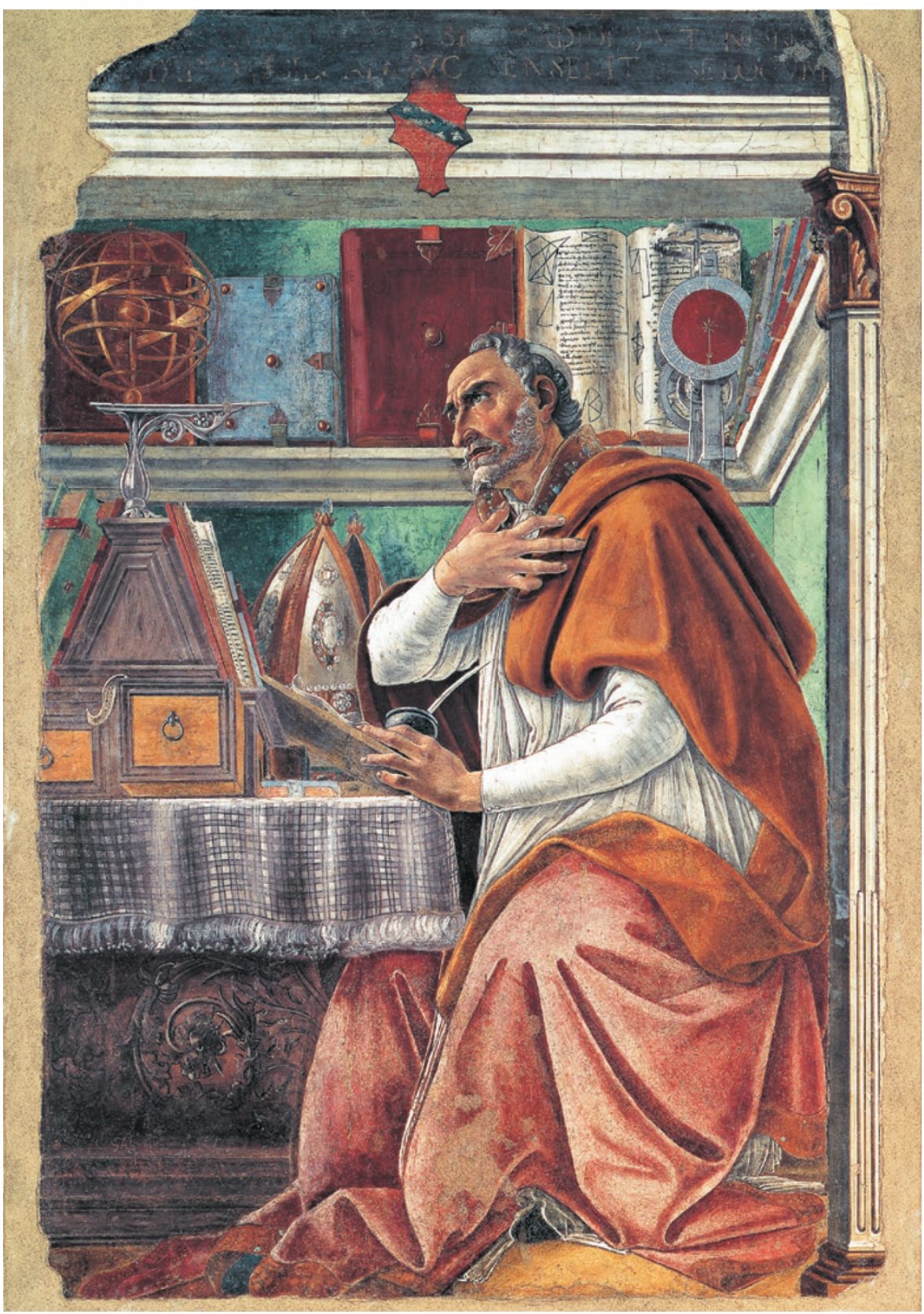

Sandro Botticelli depicts Saint Augustine with mathematical trappings such as an armillary sphere.

$\mathrm{T}$ hroughout history, mathematics has developed as part of humanity's search for patterns. When I explored mathematics in cultures East and West for my book Mathematics and Art: A Cultural History (Princeton University Press, 2016), I discovered that many artists have expressed their cultural world views through works that embody these patterns. From the classical period more than two millennia ago, through the Chinese dynasties, the Western Renaissance and the mathematics and physics of the twentieth and twenty-first centuries, art and architecture have incorporated the mathematics of their day in deep ways.

How a culture conceives of ultimate reality - whether it is composed of atoms or a 'world soul' - relates directly to how people think about mathematics. Plato looked to pure form: abstractions such as numbers or spheres that resided outside mundane time and space. He described a divine being, the demiurge (from the Greek for 'craftsman'), who created the natural world by imposing these archetypal forms onto formless matter. The thinker Augustine of Hippo in North Africa later bridged classical knowledge and Christian theology in De Doctrina Christiana (around AD 400). Augustine - who had studied the seven liberal arts, including geometry and astronomy, before his conversion to Christianity - noted that if the Platonists "have said things which are indeed true and well accommodated to our faith, they should not be feared".

More than a millennium later, that mingling of Hellenic and Christian thought was expressed by Italian Renaissance artist Sandro Botticelli. In a 1480 fresco in the Ognissanti church in Florence, Botticelli portrayed Augustine as a scholar-saint wearing clerical robes with an open treatise on geometry and a weight-driven clock nearby. He looks heavenwards, seeking the order that the Christian God (like Plato's demiurge) imposed on creation by dividing light from darkness. But Botticelli's rendering of Augustine also reveals the influence of classical Greco-Egyptian mathematician Ptolemy, who reasoned that in the ideal perfection of the heavens, bodies such as planets are spherical and move in circular paths at a constant speed. An Earth-centred Ptolemaic armillary sphere appears in the upper lefthand corner of the fresco.

Botticelli's mathematical awareness extended to an understanding of linear perspective: he portrays Augustine as a solid body inhabiting an architectural space. Decades earlier, his fellow Florentine Filippo Brunelleschi had invented a way to visualize a geometric projection from a given viewpoint, based on findings in optics by medieval Islamic scholar Ibn al-Haytham - the first to explain vision as the eye's passive response to light (J. Al-Khalili Nature 518, 164-165; 2015). Brunelleschi's experimentation allowed Florentine artists to paint figures not floating in a golden mist, but right here, right now, in a believably depicted natural world.

Ancient Greek mathematicians abstracted and generalized from the particular to the whole; ancient Chinese mathematicians did not generalize, but focused on particular examples as paradigms. The Chinese were adept at creating numerical patterns such as the Luoshu, in which even-odd, black-white 


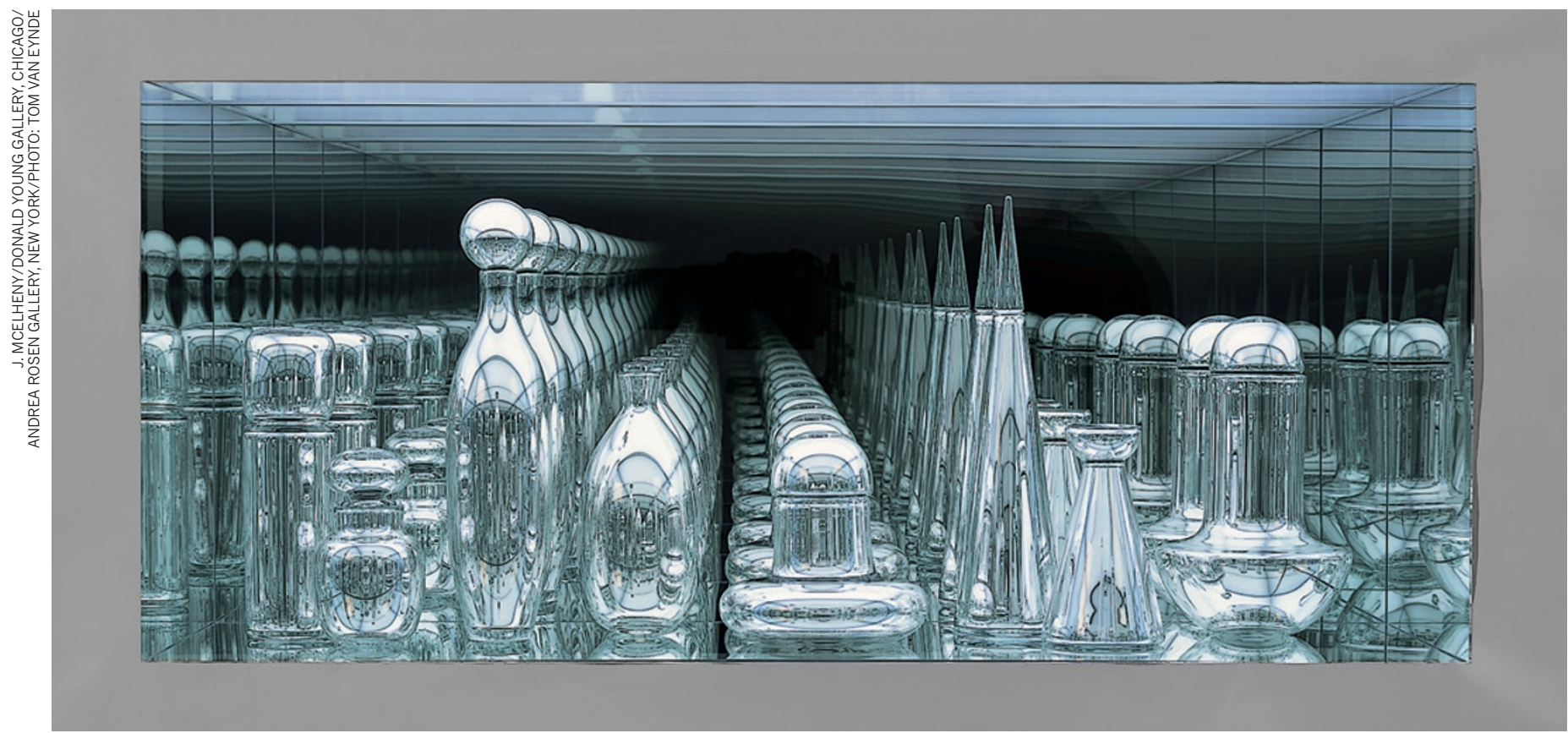

Czech Modernism Mirrored and Reflected Infinitely (2005) by Josiah McElheny reflects an enclosed world to infinity.

or yin-yang pairs of numbers symbolizing the elements (metal, fire, water, wood, earth) are arranged so that the rows, columns and diagonals add up to the same number. This 'magic square' reflects the Taoist view that the natural world is a balance of parts, which came into being by self-assembly following the ultimately unknowable Tao (way) of nature. Japanese artist Tatsuo Miyajima echoes this outlook in his 1998 artwork Keep Changing, Connect with Everything, Continue Forever, a sparkling, blinking grid of red light-emitting diodes. The overall pattern is too complex for the human eye and mind to discern, but, like the natural world, it is a unity of fluctuating parts.

While Chinese mathematicians studied dynamic patterns in harmonic balance, Western mathematics rested on a rock-solid foundation put in place by Euclid, a follower of Plato, in his treatise Elements (around 300 вс). Euclid organized certain truths (for example, that all right angles are equal), into an axiomatic system that undergirded Western mathematics until the nineteenth century, when other geometries were discovered. In his Foundations of Geometry (1899), the German mathematician David Hilbert cut the ties that bound points and planes to the world, rewriting geometry as an internally consistent arrangement of meaning-free signs. Inspired by Hilbert's formalist approach, the Russian artist Aleksandr Rodchenko reduced painting to its essence a monochrome rectangle - in works such as

$\rightarrow$ NATURE,COM

Visit our blog on science in culture: go.nature.com/2mn9yk
The reductionist impulse survives today in artists such as Josiah McElheny, who, echoing Hilbert, created a self-contained arrangement of abstract signs, Czech Modernism Mirrored and Reflected Infinitely (2005). McElheny transformed eight glass bottles into mirrors with an interior coating of silver. Set within a mirrored box, they reflect all light to infinity. Like Hilbert's mute marks, they are uncontaminated in their selfenclosed world: the front of the box is a oneway mirror, reflective surface facing inwards.

In Mathemat-

ics and Art, I also

trace the tension between accounts of deterministic laws of cause and effect in nature, and rebellions against the 'dehumanizing' nature of such laws and their associated mathematics. In antiquity, the Greek rationalist Democritus described a mechanical, predictable Universe made of inert atoms. But in Plato's cosmos, humanity's attainment of certain knowledge was unpredictable: only after lengthy contemplation "does truth flash upon the soul, like a flame kindled by a leaping spark".

In the twentieth century, this tension was expressed in rival philosophical interpretations of the subatomic realm of quantum physics. The leading contender was the Copenhagen interpretation, put forth in 1927 by Niels Bohr and Werner Heisenberg, who declared that nature is fundamentally indeterministic and reality is in the mind of the observer. The minority view held out for universal knowledge and a physical world independent of human observation. Its spokesman, an exasperated Albert Einstein, exclaimed: "The moon is there even when I'm not looking at it." After the Second World War, Bohr and Heisenberg expressed the Copenhagen interpretation in popular science writings (such as Heisenberg's Physics and Philosophy, 1959), in which they announced that the classical ideals of rationality and objectivity were naive. Such declarations contributed to postmodernism, a stance widely adopted by artists.

Ultimately, mathematicians and artists often hybridize Western and Eastern traditions, which began to merge after Charles Darwin published On the Origin of Species in 1859. As Western theology made way for science, more and more features of the human body and mind yielded to the explanatory power of biology, physiology and psychology. This cataclysmic shift prompted many Westerners to integrate into their work the Taoist view of nature as a balance of parts coming together by self-assembly.

The scientific world view is a hybrid of Western and Eastern traditions, expressing the philosophical conviction that the natural world has a wholeness with which humans are one. Today, there are new manifestations of the quest for unity. Scientists and mathematicians continue to search for patterns in the physical Universe that in turn inspire artists who strive to express our global cultural view of reality.

Lynn Gamwell is a lecturer on the history of art, mathematics and science at the School of Visual Arts in New York. Her previous books include Exploring the Invisible.

e-mail:lgamwell@sva.edu 